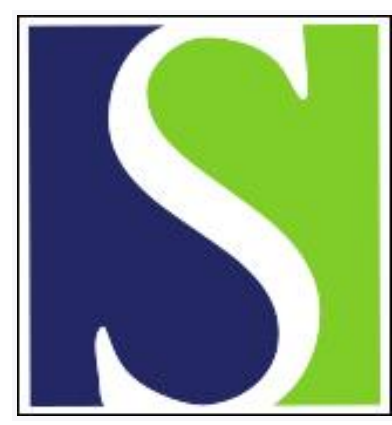

Scand J Work Environ Health 1994;20(1):27-33

https://doi.org/10.5271/sjweh.1432

Issue date: $01 \mathrm{Feb} 1994$

Eye discomfort and work with visual display terminals.

by Bergqvist UO, Knave BG

Affiliation: Department of Neuromedicine, National Institute of Occupational Health, Solna, Sweden.

This article in PubMed: www.ncbi.nlm.nih.gov/pubmed/8016596

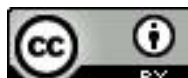




\title{
Eye discomfort and work with visual display terminals
}

\author{
by Ulf OV Bergqvist, MSci Techn, Bengt G Knave, MD'
}

\begin{abstract}
BERGQVIST U, KNAVE B. Eye discomfort and work with visual display terminals. Scand $J$ Work Environ Health 1994;20:27-33. OBjectives - The aim of this study was to investigate the relationships between eye discomfort symptoms and work with visual display terminals among routine office workers. METHODs - Three hundred and twenty-seven office workers and their work stations were investigated by means of questionnaires and worksite investigations. The data were subjected to multivariate logistic regression analyses. REsults - The occurrence of eye discomfort increased as the extent of VDT work increased, as did the specific symptoms of sensitivity to light and smarting, gritty feeling, or redness. The use of spectacles during visual display terminal work, age, stomach stress reaction, distances between the eye and different visual task objects, as well as the vertical position of the terminal also influenced certain symptoms. Having (i) the terminal at about eye level during prolonged terminal work, (ii) using monofocal glasses during terminal work in situations with large distance variations to visual task objects, or (iii) being elderly with prolonged terminal work and reporting stomach stress all led to increased odds ratios for certain eye discomfort symptoms. Conclusions - The use of a visual display terminal in routine office work is associated with an increased occurrence of certain eye discomfort symptoms. This association is affected also by the presence of certain other individual and ergonomic factors.
\end{abstract}

Key terms: age, ergonomic conditions, spectacles, stress, VDT.

Eye discomfort among visual display terminal (VDT) workers was first described in 1973 by Hultgren \& Knave (1). Since then several studies have investigated this association. Our study is part of an investigation of a cohort of routine office workers in Stockholm, Sweden, with emphasis on VDT work. In a first cross-sectional examination in 1981, eye discomfort was more common among VDT users than among non-VDT users (2). Between 1981 and 1987 , the cumulative incidence of eye discomfort increased with the extent of VDT work (3). The questions elucidated in this study - a second cross-sectional investigation in 1987 of the same cohort are "What individual, ergonomic, and organizational variables are associated with eye discomfort among routine office workers, do VDT users experience a higher prevalence of eye discomfort than non-VDT users, after adjustments for the possible confounding effects of these other variables, and is the effect of VDT work on various eye discomfort symptoms - if any - modified by these variables?"

\section{Subjects and methods}

\section{Cohort description and data acquisition}

In 1981, 588 office workers with or without VDT work in seven companies were selected for inclusion

\footnotetext{
' Department of Neuromedicine, National Institute of Occupational Health, Solna, Sweden.
}

Reprint requests to: Mr U Bergqvist, Department of Neuromedicine, National Institute of Occupational Health, S17152 Solna, Sweden. in the study. Most $(\mathrm{N}=535,91 \%)$ of them participated. By 1987, 353 individuals remained in the group - the others had quit working in the respective company, retired, or the like. For $150(82 \%)$ of the dropouts, data were obtained that described whether various types of discomfort (including eye discomfort) or VDT work had contributed to their decision to quit the workplace. Only one individual reported that eye discomfort had influenced the decision.

A questionnaire with details on eye discomfort, individual factors, and work conditions was distributed to the 353 persons who remained in the study, with a $93 \%$ response rate $(\mathrm{N}=327)$. Ergonomic conditions were measured for $228(88 \%)$ of the 260 VDT users. The relative humidity at the workplaces was obtained for $203(78 \%)$ of the VDT users.

\section{Variables describing eye discomfort}

The respondents were asked about the occurrence of eight different eye symptoms. "Any discomfort" was the occurrence of any of these symptoms, while the variable "moderate discomfort" described the occurrence of only those symptoms that were more frequent or intense. (For a more-detailed description, see reference 2.) The occurrence of smarting (S), gritty feeling $(G)$, or redness $(R)$ (regardless of frequency and intensity) were collected into the variable SGR, on the assumption that these symptoms represent identical or similar etiologies. Occurrences of itching, aches, sensitivity to light, teariness, and dryness symptoms were analyzed separately. 


\section{Variables describing work with visual display terminals}

"No VDT use" indicated that the respondent did not use a VDT or that his or her use was normally less than $5 \mathrm{~h}$ a week. The VDT users were divided into those with normally $5-20 \mathrm{~h}$ a week and more than $20 \mathrm{~h}$ a week. The type of VDT work was categorized as data entry (data entry or word processing or both) and interactive work (data acquisition, interactive work, and mixed work or programming or both). Interactive work implied longer viewing time towards the screen than data entry work. Thus, when the highest odds ratio for a discomfort was found for those doing interactive work for more than $20 \mathrm{~h}$ a week, the effect of the total time looking at the screen ("VDT viewing time") was analyzed. This estimate was based on VDT work types, the total VDT work time, and reported estimates of the fraction VDT viewing time/VDT worktime for different VDT work types $(2,4-6)$.

\section{Other variables}

The variable "VDT glasses" described the use of spectacles or contact lenses in the VDT work situation and was separated into none, monofocal, or others (bifocal or progressive glasses and contact lenses). "Stomach stress" reactions were based on responses indicating an upset stomach, while "tiredness" reactions were related to the inability to relax and other such symptoms (7). "Negative affectivity" corresponded to a personality trait expressed as "anger, disgust, scorn, guilt, fearfulness, and depression" that has been suggested to influence the reporting of discomfort (8-10). Age, gender, and smoking (yes or no) were also used in the analysis.

"Organizational influence" was the opportunity to take initiative, influence planning, develop oneself at work, and other such factors. "Rest-break opportunity" was based on the ability to take unscheduled breaks. "Flexibility of work task" described whether workers could shift their work tasks to another day, availability of several tasks, and the like. "Work pace" summed the perceived demands for concentration, time pressure, inability to take a breather, and the like (7). Other variables were "company type," "ability to change work if tired," "overtime frequency," and "overtime on short notice."

The angle between the horizontal plane from the eyes and the line between the eyes and the center of the VDT was measured for the vertical position of the VDT. "High" meant an angle between 0 and 20 degrees below the horizontal line. "Low" meant a VDT at a lower level, for about $90 \%$ the level being between 20 and 30 degrees. The distances were measured between the eyes and the following three task objects: the VDT, the keyboard, and the document or document holder. The maximum difference between these three distances was also noted. In addition, observations were made regarding the oper- ator's head position (bent forward or not) and the presence of glare on the VDT. The observations and measurements corresponded to "normal" positions in the most common work situation. The average relative humidity during a workweek was also measured; for details see reference 11 .

\section{Analysis}

For each eye discomfort variable, a multivariate model was constructed which included "VDT use," as well as important individual and organizational variables, in order to adjust for their possible confounding effects (table 1). The procedure for the construction of this model was that, at first, six variables describing individual conditions that were considered relevant for eye discomfort were selected, and only those showing a substantial association with the symptom in question were retained and combined in a multivariate model. This model was then extended by including the variable "VDT use" and also eight selected organizational variables. The number of variables in the model was reduced through the elimination of variables with low adjusted odds ratios at each step in order to increase the precision, but only insofar as odds ratios of other variables were unaffected by this elimination (12). Among the VDT users, the impacts of eight ergonomic variables and negative affectivity were also evaluated (table 2 ). The procedure for the construction of this second model was analogous with that of the first.

Some interactions were investigated, with the aim of detecting whether a variable describing VDT work conditions and another variable had a combined effect on eye discomfort in excess of the sum of the effect of each variable in isolation (13). The selection of interactions to be evaluated was based on plausibility of the interactions.

Estimates of univariate (crude) and stratum-specific odds ratios and their $95 \%$ precision-based confidence intervals $(95 \% \mathrm{CI})$ were computed. (For both theoretical and practical reasons, the odds ratios rather than the prevalence ratios were computed.) Unconditional maximum likelihood estimates were obtained from the multivariate logistic regression analysis. The FREQ and CATMOD procedures in the SAS system (14) were used for these analyses. When the number of individuals was small, the results were verified by either reducing the number of variables in the model (in the absence of confounding) or using exact methods (Fisher). Linear trends for odds ratios were calculated as suggested by Rothman (13).

\section{Results}

Tables 1 and 2 show the associations found between the various types of eye discomfort and VDT work with control for individual, organizational and (for table 2) ergonomic variables. Increasing odds ratios with increasing VDT use in hours per week were 
observed for any discomfort, sensitivity to light, and possibly also for SGR. For sensitivity to light, the VDT users performing interactive work had higher odds ratios than those performing data entry work. Therefore, an analysis of VDT viewing time was performed among the VDT users. The precisions of the odds ratios for VDT viewing time were lower, a linear trend for the odds ratio of sensitivity to light as a function of VDT viewing time having a slope of $0.09(-0.06$ to 0.24$)$ per hour of viewing time.

For three of the six individual variables (age, VDT glasses, and stomach stress), odds ratios were elevated for certain symptoms (as seen in tables 1 and
2). For gender, the crude analysis resulted in odds ratios between 1.5 and 2 (women versus men) for some symptoms, but these odds ratios were considerably reduced in the multivariate models, leading to the elimination of the gender indicator from the models. Smoking and tiredness reactions did not have elevated crude odds ratios. For work pace, elevated odds ratios appeared in some models (table 1). In table 2 , this variable was not retained due to the reduction of these odds ratios by the introduction of the variable negative affectivity. Other organizational variables had odds ratios of less than 1.5 in the multivariate models and were not retained. Six ergonom-

Table 1. Associations between eye discomfort and the use of a visual display terminal (VDT). The comparisons have been made between VDT users and non-VDT users. The models include important individual and organizational factors.

\begin{tabular}{|c|c|c|c|c|c|}
\hline \multirow{3}{*}{ Discomfort ${ }^{a}$} & \multicolumn{4}{|c|}{ VDT use } & \multirow{3}{*}{$\begin{array}{l}\text { Other factors in the models with respective } \\
\text { odds ratios (OR) and } 95 \% \text { confidence intervals } \\
(95 \% \mathrm{Cl})\end{array}$} \\
\hline & \multicolumn{2}{|c|}{$5-20 \mathrm{~h} \cdot$ week $^{-1}$} & \multicolumn{2}{|c|}{$>20 \mathrm{~h} \cdot$ week $^{-1}$} & \\
\hline & $\begin{array}{l}\text { Odds } \\
\text { ratio }\end{array}$ & $95 \% \mathrm{Cl}$ & $\begin{array}{l}\text { Odds } \\
\text { ratio }\end{array}$ & $95 \% \mathrm{Cl}$ & \\
\hline $\begin{array}{l}\text { Any } \\
\text { discomfort } \\
(\mathrm{N}=316, \mathrm{DP}=70 \%)\end{array}$ & 2.9 & $1.4-6.1$ & 5.7 & $2.7-12.0$ & $\begin{array}{l}\text { Stomach stress (seidom: OR } 2.5,95 \% \text { Cl } 1.4-4.4 \\
\text { often: OR } 4.9,95 \% \mathrm{Cl} 2.0-11.7 \text { ) } \\
\text { Company type (newspaper production: } \\
\text { OR } 2.6,95 \% \mathrm{Cl} 1.2-5.9 \text {; postal office: OR } 3.8 \text {, } \\
95 \% \mathrm{Cl} 1.6-8.8 \text {; insurance company: OR } 3.1 \text {, } \\
95 \% \mathrm{Cl} 1.4-6.9 \text { ) } \\
\text { Work pace (moderate: OR } 2.4,95 \% \mathrm{Cl} 1.2-5.0 \text {; } \\
\text { high: OR } 1.8,95 \% \mathrm{Cl} 0.9-4.0)^{\mathrm{e}}\end{array}$ \\
\hline $\begin{array}{l}\text { Moderate } \\
\text { discomfort } \\
(N=316, D P=29 \%)\end{array}$ & 1.4 & $0.6-3.2$ & 2.4 & $1.1-5.0$ & $\begin{array}{l}\text { Stomach stress (seldom: OR } 2.2,95 \% \text { Cl } 1.2-4.0 \\
\text { often: OR } 4.2,95 \% \mathrm{Cl} 2.1-8.4)^{\mathrm{c}} \\
\text { Work pace (moderate OR } 1.8,95 \% \mathrm{Cl} 0.8-3.9 \\
\text { high: OR } 2.2,95 \% \mathrm{Cl} 1.0-5.0)^{e}\end{array}$ \\
\hline $\begin{array}{l}\text { Smarting, } \\
\text { gritty feeling, } \\
\text { redness } \\
(\mathrm{N}=307, \mathrm{DP}=56 \%)\end{array}$ & 2.0 & $1.0-4.0$ & 3.5 & $1.9-6.7$ & $\begin{array}{l}\text { Stomach stress (seldom: OR } 1.7,95 \% \mathrm{Cl} 1.0-2.8 \text {; } \\
\text { often: OR } 2.6,95 \% \mathrm{Cl} 1.3-5.1)^{\mathrm{c}} \\
\text { Work pace (moderate: OR } 1.7,95 \% \mathrm{Cl} 0.9-3.3 \text {; } \\
\text { high: OR } 1.7,95 \% \mathrm{Cl} 0.8-3.4)^{\mathrm{e}}\end{array}$ \\
\hline $\begin{array}{l}\text { Itching } \\
(N=292, D P=34 \%)\end{array}$ & 3.7 & $1.5-9.5$ & 3.5 & $1.4-8.5$ & $\begin{array}{l}\text { VDT giasses (monofocal: OR } 2.3,95 \% \text { Cl } 1.3-4.2 \text {; } \\
\text { others: OR } 1.4,95 \% \mathrm{Cl} 0.6-3.7)^{f} \\
\text { Stomach stress (seldom: OR } 1.6,95 \% \mathrm{Cl} 0.9-2.8 \text {; } \\
\text { often: OR } 2.8,95 \% \mathrm{Cl} 1.4-5.7)^{\mathrm{c}} \\
\text { Work pace (moderate: OR } 1.6,95 \% \mathrm{Cl} 0.8-3.4 ; \\
\text { high: } 1.7,95 \% \mathrm{Cl} 0.8-3.7)^{\mathrm{e}}\end{array}$ \\
\hline $\begin{array}{l}\text { Aches } \\
(N=297, D P=15 \%)\end{array}$ & 2.2 & $0.7-7.2$ & 2.5 & $0.8-7.7$ & $\begin{array}{l}\text { VDT glasses (monofocal: OR } 2.1,95 \% \mathrm{Cl} 1.0-4.5 \\
\text { others: OR } 1.8,95 \% \mathrm{Cl} 0.6-5.9)^{f}\end{array}$ \\
\hline $\begin{array}{l}\text { Sensitivity } \\
\text { to light } \\
(\mathrm{N}=316, \mathrm{DP}=40 \%)\end{array}$ & 1.6 & $0.8-3.3$ & 2.7 & $1.4-5.2$ & $\begin{array}{l}\text { Age }(40-49 \text { years: OR } 1.4,95 \% \mathrm{Cl} 0.8-2.7 \\
\geq 50 \text { years: OR } 1.8,95 \% \mathrm{Cl} 1.0-3.2)^{\mathrm{g}} \\
\text { Stomach stress (seldom: OR } 1.9,95 \% \mathrm{Cl} 1.1-3.2 ; \\
\text { often: OR } 2.5,95 \% \mathrm{Cl} 1.3-4.8)^{\mathrm{c}}\end{array}$ \\
\hline $\begin{array}{l}\text { Teariness } \\
(\mathrm{N}=312, \mathrm{DP}=24 \%)\end{array}$ & 1.1 & $0.5-2.6$ & 1.7 & $0.8-3.6$ & $\begin{array}{l}\text { Age }(40-49 \text { years: OR } 2.0,95 \% \text { Cl } 0.9-4.3 \\
\geq 50 \text { years: OR } 3.0,95 \% \text { Cl } 1.4-6.3)^{9} \\
\text { Stomach stress (seldom: OR } 1.7,95 \% \text { Cl } 0.9-3.2 \\
\text { often: } \text { OR } 3.3,95 \% \text { Cl } 1.6-6.7)^{\circ}\end{array}$ \\
\hline $\begin{array}{l}\text { Dryness } \\
(\mathrm{N}=294, \mathrm{DP}=20 \%)\end{array}$ & 2.4 & $0.7-8.3$ & 2.9 & $0.9-9.5$ & $\begin{array}{l}\text { Age ( } 40-49 \text { years: OR } 0.5,95 \% \text { Cl } 0.2-1.1 ; \\
\geq 50 \text { years: OR } 0.6,95 \% \mathrm{Cl} 0.3-1.4)^{9} \\
\text { VDT glasses (monofocal: OR } 2.3,95 \% \mathrm{Cl} 1.0-5.5 ; \\
\text { others: OR } 11.6,95 \% \mathrm{Cl} 4.0-34.0)^{\dagger} \\
\text { Stomach stress (seldom: OR } 1.5,95 \% \mathrm{Cl} 0.9-3.3 ; \\
\text { often: OR } 3.8,95 \% \mathrm{Cl} 1.7-8.6)^{c}\end{array}$ \\
\hline
\end{tabular}

\footnotetext{
a Number of individuals in the final model $(\mathrm{N})$ and discomfort prevalence (DP) noted.

b Prevalence of the VDT use condition: $5-20 \mathrm{~h} \cdot$ week $^{-1}: 32 \% ;>20 \mathrm{~h} \cdot$ week $^{-1}: 48 \%$.

c Compared with never stomach stress reactions.

d Compared with travel agency.

e Compared with low work pace.

1 Compared with no use of glasses during VDT work or no VDT work (others = use of bifocals or progressive glasses or contact lenses).

g Compared with those $<40$ years old.
} 
Table 2. Associations between eye discomfort and the use of a visual display terminal (VDT). The comparisons have been made within the VDT user group. The models include important individual, organizational, and ergonomic factors. ${ }^{a}$

\begin{tabular}{|c|c|c|c|c|c|}
\hline \multirow{3}{*}{ Discomfort } & \multicolumn{4}{|c|}{ VDT use $\mathrm{e}^{\mathrm{b}}$} & \multirow{3}{*}{$\begin{array}{l}\text { Other factors in the final models with their } \\
\text { odds ratios (OR) and } 95 \% \text { confidence intervals } \\
(95 \% \mathrm{Cl})\end{array}$} \\
\hline & \multicolumn{2}{|c|}{$>20 \mathrm{~h} \cdot$ week $^{-1}$} & \multicolumn{2}{|c|}{ Interactive } & \\
\hline & $\begin{array}{l}\text { Odds } \\
\text { ratio }\end{array}$ & $95 \% \mathrm{Cl}$ & $\begin{array}{l}\text { Odds } \\
\text { ratio }\end{array}$ & $95 \% \mathrm{Cl}$ & \\
\hline $\begin{array}{l}\text { Any } \\
\text { discomfort } \\
(\mathrm{N}=202)\end{array}$ & 3.0 & $1.4-6.1$ & 0.7 & $0.3-1.6$ & $\begin{array}{l}\text { Stomach stress (seldom: OR 3.8,95\% Cl 1.8-7.9; } \\
\text { often: OR 16.6, 95\% Cl 3.6-55.8) } \\
\text { VDT vertical position (OR } 1.8,95 \% \mathrm{Cl} 0.9-3.8)^{\mathrm{d}}\end{array}$ \\
\hline $\begin{array}{l}\text { Moderate } \\
\text { discomfort } \\
(\mathrm{N}=195)\end{array}$ & 1.2 & $0.6-2.3$ & 1.2 & $0.6-2.4$ & $\begin{array}{l}\text { Stomach stress (seldom: OR } 2.0,95 \% \mathrm{Cl} 1.0-4.2 \text {; } \\
\text { often: OR } 4.4,95 \% \mathrm{Cl} 1.9-10.4)^{\mathrm{c}} \\
\text { Eye-VDT distance }<60 \mathrm{~cm}(\mathrm{OR} 2.5 \\
95 \% \mathrm{Cl} 1.3-4.7)^{\mathrm{e}}\end{array}$ \\
\hline $\begin{array}{l}\text { Smarting, } \\
\text { gritty feeling, } \\
\text { redness } \\
(N=189)\end{array}$ & 1.4 & $0.8-2.8$ & 0.9 & $0.5-1.7$ & $\begin{array}{l}\text { Age }(40-49 \text { years: OR } 1.8,95 \% \mathrm{Cl} 0.8-3.9 \\
\geq 50 \text { years: OR } 1.8,95 \% \mathrm{Cl} 0.8-3.9)^{f} \\
\text { VDT vertical position }(\mathrm{OR} 1.7,95 \% \mathrm{Cl} 0.9-3.2)^{\mathrm{d}}\end{array}$ \\
\hline $\begin{array}{l}\text { Itching } \\
(N=185)\end{array}$ & 1.2 & $0.6-2.4$ & 1.3 & $0.6-2.9$ & 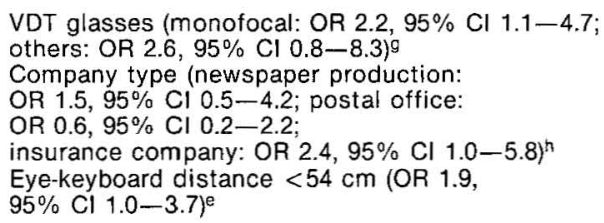 \\
\hline $\begin{array}{l}\text { Sensitivity } \\
\text { to light } \\
(N=191)\end{array}$ & 2.3 & $1.1-4.5$ & 1.9 & $1.0-3.7$ & $\begin{array}{l}\text { Age (40-49 years: OR } 1.3,95 \% \text { Cl } 0.6-2.8 \\
\geq 50 \text { years: OR } 1.9,95 \% \mathrm{Cl} 0.8-4.1)^{\dagger} \\
\text { Stomach stress (seldom: OR } 1.7,95 \% \mathrm{Cl} 0.8-3.4 \text {; } \\
\text { often: OR } 4.3,95 \% \mathrm{Cl} 1.8-10.2)^{\mathrm{c}} \\
\text { VDT vertical position (OR } 1.9,95 \% \mathrm{Cl} 1.0-3.6)^{\mathrm{d}}\end{array}$ \\
\hline $\begin{array}{l}\text { Dryness } \\
(N=188) \\
(N=157)\end{array}$ & 1.0 & $0.4-2.3$ & 0.6 & $0.3-1.3$ & $\begin{array}{l}\text { VDT glasses (monofocal: OR } 3.4,95 \% \mathrm{Cl} 1.3-9.2 \text {; } \\
\text { others: OR } 12.3,95 \% \mathrm{Cl} 3.4-45.1)^{\mathrm{g}} \\
\text { Stomach stress (seldom: OR 1.6, 95\% Cl } 0.7-3.8 \text {; } \\
\text { often: OR } 2.4,95 \% \mathrm{Cl} 0.9-6.0)^{\mathrm{c}} \\
\text { Relative humidity }<30 \%(\mathrm{OR} 2.5,95 \% \mathrm{Cl} 1.1-5.5)^{\mathrm{i}} \\
\text { Maximum difference in eye-object } \\
\text { distances }>10 \mathrm{~cm} \text { (OR } 2.8,95 \% \mathrm{Cl} 1.0-7.3)^{\mathrm{j}, \mathrm{k}} \\
\text { Specular glare present (OR } 3.3,95 \% \mathrm{Cl} 1.2-8.7)^{\mathrm{j}, 1}\end{array}$ \\
\hline
\end{tabular}

a The final models for aches and teariness did not retain any ergonomic terms, thus eliminating the merit of models apart from those shown in table 1.

b $>20 \mathrm{~h}$. week ${ }^{-1}$ versus $<20 \mathrm{~h} \cdot$ week $^{-1}$; interactive work versus data entry work. Prevalence of the VDT work condition within the total VDT user group; $>20 \mathrm{~h} \cdot$ week $^{-1}: 60 \%$; interactive : $65 \%$.

- Compared with never stomach stress reactions.

¿ Center of VDT at $0-20$ degrees below eye level compared with further down.

e Compared with VDT or keyboard at longer distances.

f Compared with those $<40$ years old.

$g$ Compared with no use of glasses during VDT work.

h Compared with travel agency.

Compared with a relative humidity of $\geq 30 \%$.

1 Another model was used to evaluate eye-object differences and glare (apart from relative humidity, terms of the model shown were present with similar odds ratios).

k Compared with distance differences of $<10 \mathrm{~cm}$.

1 Compared with no glare.

ic variables (VDT vertical position, distance to VDT, distance to keyboard, maximum difference in eyetask object distances, specular glare, and relative humidity) were retained for at least some symptoms (table 2). The other two were eliminated due to low odds ratios.

Some interactions in the excess of additivity were indicated between a variable describing VDT work and certain individual or ergonomic variables, albeit with low precisions. Having a VDT viewing time of more than $9 \mathrm{~h} \cdot$ week $^{-1}$ and having the VDT placed at about eye level was associated with an excess occurrence of sensitivity to light (figure 1). Likewise, working more than $20 \mathrm{~h}$ a week at a VDT and having the VDT in a high vertical position was associated with an excess occurrence of any discomfort, with an odds ratio of $5.2(\mathrm{~N}=191,95 \% \mathrm{CI}$ 1.7-15.9).

Individuals who used monofocal glasses during their VDT work and had fairly large $(>10 \mathrm{~cm})$ differences between distances from their eyes to different task objects had an excess occurrence of dryness symptoms (figure 2 ). The odds ratio for the factor combination was 6.7 (95\% CI $0.7-68.0)$. The number of individuals available for this analysis was limited, especially in the reference category $(\mathrm{N}=14)$. In an a posteriori model, users of monofocal glasses and large object differences had an odds ratio of 2.2 


\begin{tabular}{|c|c|c|}
\hline \multicolumn{3}{|c|}{ Legend } \\
\hline & $\begin{array}{l}\text { Estimated total } \\
\text { VDT viewing } \\
\text { time per week }\end{array}$ & $\begin{array}{l}\text { Vertical position of } \\
\text { the VDT, compared } \\
\text { to the eye level }\end{array}$ \\
\hline & $\leq 9 \mathrm{~h}$ & $\begin{array}{l}20-30^{\circ} \text { below- } \\
\text { horizontal }\end{array}$ \\
\hline & $>9 \mathrm{~h}$ & - " - \\
\hline & $\leq 9 \mathrm{~h}$ & $\begin{array}{l}0-20^{\circ} \text { below } \\
\text { horizontal }\end{array}$ \\
\hline & $>9 \mathrm{~h}$ & - " \\
\hline & \multicolumn{2}{|c|}{$\begin{array}{l}95 \% \text { confidence interval (only the } \\
\text { lower limit shown) }\end{array}$} \\
\hline
\end{tabular}

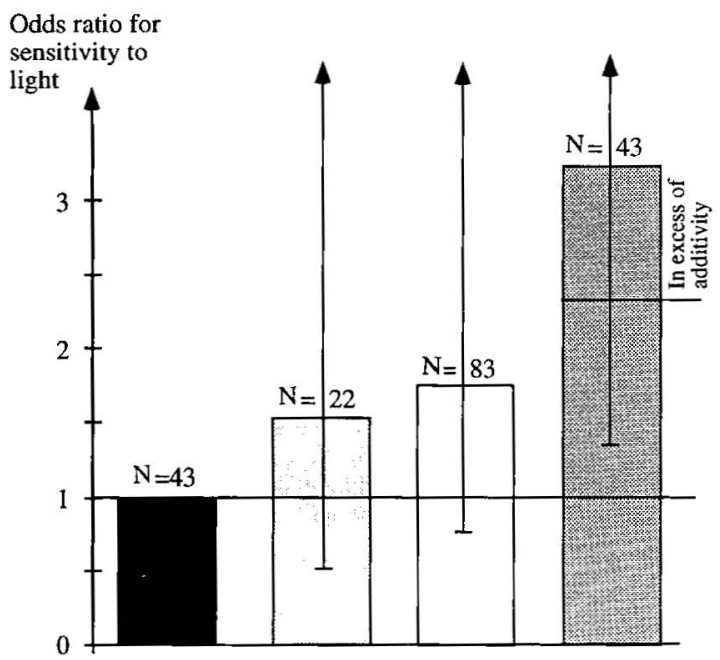

Figure 1. Associations between sensitivity to light and combinations of the estimated viewing time and the vertical position of the visual display terminal (VDT) $(N=191)$. All comparisons were made within the VDT user group. In the group having a VDT viewing time of more than $9 \mathrm{~h}$ a week and the VDT placed $0-20$ degrees below eye level, the odds ratio in excess of additivity is indicated. A few individuals had a vertical glance direction downwards greater than 30 degrees; they have been included in the 20 - to 30 -degree group.

(95\% CI $0.5-10.2)$ if less than 40 years of age, and 4.9 (95\% CI 1.9-13.0) if at least 40 years of age, compared with those lacking the combination of both factors.

Older ( $\geq 50$ years) individuals who reported stomach stress reactions and who worked for more than $20 \mathrm{~h}$ a week at a VDT had an excess occurrence of teariness, with an odds ratio of 9.0 (95\% CI 2.2$36.4)$ compared with younger persons ( $<40$ years) who reported stomach stress and worked less than 20 hours a week at a VDT. The odds ratios of the other VDT user groups reporting stomach stress were lower, but they increased both with age and with the amount of VDT use. Among individuals who did not report stomach stress, the odds ratios did not increase with age or VDT use.

\begin{tabular}{|ll|}
\hline $\begin{array}{l}\text { Legend } \\
\begin{array}{l}\text { Use of glasses } \\
\text { woring VDT }\end{array}\end{array}$ & $\begin{array}{l}\text { Maximum difference } \\
\text { in distances from eyes } \\
\text { to VDT, keyboard or } \\
\text { manuscript }\end{array}$ \\
\hline none & $<10 \mathrm{~cm}$ \\
none & $\geq 10 \mathrm{~cm}$ \\
monofocal & $<10 \mathrm{~cm}$ \\
monofocal & $\geq 10 \mathrm{~cm}$ \\
95\% confidence interval (only the \\
lower limit shown)
\end{tabular}

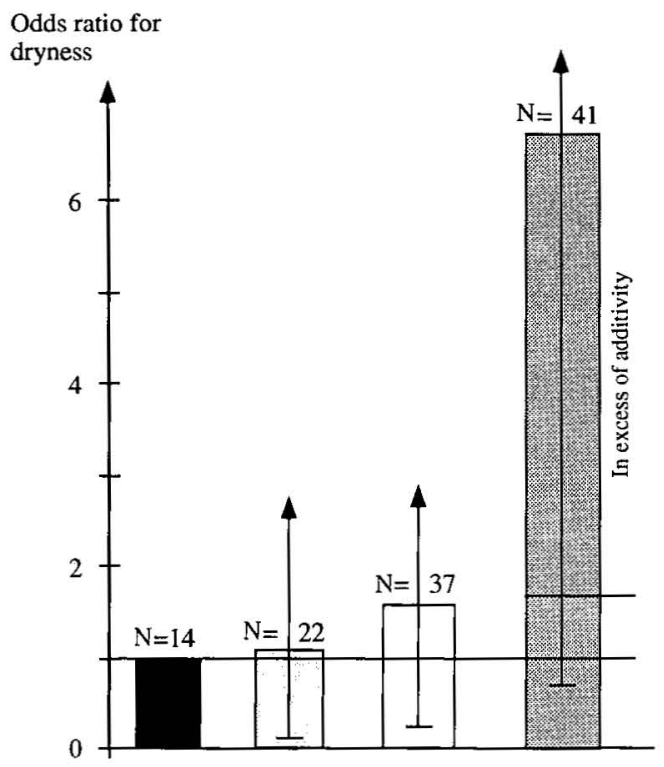

Figure 2. Associations between dryness symptoms and combinations of the use of monofocal glasses during visual display terminal (VDT) work and the maximum difference between distances from the eyes to the VDT, the keyboard, or the manuscript. All of the comparisons were made within the VDT user group $(\mathrm{N}=114)$. The group using monofocal glasses at the VDT and having at least a $10-\mathrm{cm}$ difference in the distances from the eyes to different task objects had an odds ratio of $6.7(95 \% \mathrm{Cl} 0.7-68.0)$ compared with the reference group (shown in black). The odds ratio in excess of additivity is indicated. Compared with all of the other groups in combination, the odds ratio of this group was $5.2(95 \% \mathrm{Cl} 1.6-$ 16.9).

\section{Discussion}

\section{Eye discomfort and work with visual display terminals}

For any discomfort, an association was found with the current extent of VDT use. Several studies have found a higher prevalence of eye discomfort or asthenopia among VDT operators compared with nonVDT operators, or a prevalence that increased with VDT working time $(15-20)$. Other studies have failed to do so $(5,21,22)$, although a nonsignificant increase was seen at least in one study (22). In a few 
studies, mixed results appeared $(23,24)$. Thus our study, in agreement with the majority of other studies, suggests an increase in eye discomfort with VDT work or VDT work duration, also when a number of possible confounding variables are taken into account.

Several other studies have reported on specific eye discomfort symptoms with mixed results. Rossignol and her co-workers (18) found an increase in redness but not in irritating symptom prevalences with VDT work duration. Coe et al [cited from Collins et al (16)] found an increase in reported sensitivity to light ("glare") among VDT operators compared with referents. Belisario et al (15), on the other hand, failed to find associations between redness or sensitivity to light and VDT work. Teariness or itching was not significantly associated with VDT work or VDT work duration $(15,18,22)$. Coe et al [cited from Collins et al (16)] found an increase in the reporting of aches among VDT operators compared with that of referents. In summary, symptoms of smarting, gritty feeling, or redness, as well as sensitivity to light, were found to be associated with VDT work in our study, with some limited previous support from other studies.

\section{Influence of other factors on eye discomfort}

Our study has provided data suggesting the involvement of several individual and ergonomic variables with eye discomfort. Some of the variables acted as confounders of the VDT use-eye discomfort relationships. The most consistent confounder was the variable VDT glasses, followed by age and stomach stress. For the four two-factor interactions described in the Results section, the combined effect was larger in this study than the sum of the effects of each factor in isolation. While this result could have been due to chance, the plausibility of the noted interactions supports their general credibility.

Older age was associated - with limited precision - with some specific symptoms (sensitivity to light and teariness), while dryness symptoms appeared to be associated with younger age. Reported stomach stress was associated with most of the symptoms in our study. These findings correspond with those of some other studies $(16,17,19,25)$. (Most of the reviewed studies have utilized age and gender as possible confounding factors to be controlled for, but they have less often reported specific associations.) For teariness, both age and stomach stress were relevant factors, and they appeared to interact with the effect of VDT work duration. Contrary to expectations, gender was not retained as an important variable, since its effect was strongly reduced when other variables were introduced into the models containing individual and organizational factors. It should be noted that this study population included a fairly large number of older men doing routine VDT work.
There were no indications of an impact of negative affectivity on the odds ratios between VDT work and eye discomfort. The confounding effect of negative affectivity on the odds ratio of a perceived high work pace (see the Results section) could conceivably have been due to the perception of a high work pace being influenced by the negative affectivity trait.

A reduced blinking rate and widening of the ocular surface due to the raising of the viewing angle during VDT work would increase the drying of the eyes, causing eye discomfort (26-28). This hypothesis appears to be consistent with our findings that certain types of discomfort were associated with a high position of the VDT (at about eye level). The high odds ratios obtained for prolonged VDT use or viewing time in combination with a high VDT position (see, eg, figure 1) further strengthens the proposed hypothesis.

The use of glasses during VDT work was another important factor for itching, aches, and dryness symptoms in our study. Eye symptoms have been found to be associated with small refractive errors (29-31), and it is arguable that such errors would be more common among those that have found it necessary to use spectacles or contact lenses. Using contact lenses may also be a problem in relation to blink rate and tear fluid, as has already been discussed (27). Other researchers have, on the other hand, not found differences attributable to the use of glasses or contact lenses $(18,25)$. It should be noted that the population of our study was a fixed cohort, with a fairly high median age (47 years). This situation may make comparability with some other studies less clear-cut [eg, that of Rossignol et al (18), in which the median age was 34 years] and may also partly explain the larger impact of the use of glasses during VDT work in our study. In our earlier investigation in 1981, the impact of VDT glasses on the then six-year younger cohort appeared to be considerably less (32).

A low relative humidity was important for some symptoms, as has been seen also in another study (19). Another important factor for eye discomfort was short distances between the eyes and the VDT, consistent with the findings of some studies $(33,34)$ that suggested an increase in fatigue with short distances, especially in individuals with a disparity between the (shorter) viewing distance and the individual's (longer) dark convergence. For dryness, there was an apparent interaction in our study between large variations in the distance to the eye task objects and the use of monofocal glasses during VDT work. This interaction appeared to be stronger with age and could have been related to the reduced accommodative capacity of older age.

\section{Acknowledgments}

We would like to thank Ms B Floderus and Mr R Wibom for their valuable discussions and suggestions 
in the writing of this manuscript, and Ms $\AA$ Hultgren and Ms A Wibom for their data entry work on the questionnaire and worksite investigation results. We extend our thanks also to the involved companies and their employees for their cooperation.

The study was supported by grants from the Swedish Work Environment Fund.

\section{References}

1. Hultgren H, Knave B. Discomfort glare and disturbances from light reflections in an office landscape with CRT display terminals. Appl Ergon 1974;5:28.

2. Knave BG, Wibom RI, Voss M, Hedström LD, Bergqvist UOV. Work with video display terminals among office employees: I. subjective symptoms and discomfort. Scand J Work Environ Health 1985;11; 457-66.

3. Bergqvist U, Knave B, Voss M, Wibom R. A longitudinal study of VDT work and health. Int J Hum Comput Interaction 1992;4:197-219.

4. Bergqvist UOV. Video display terminals and health: a technical and medical appraisal of the state of the art. Scand J Work Environ Health 1984;10 suppl 2:187.

5. De Groot JP, Kamphuis A. Eyestrain in VDU users: physical correlates and long-term effects. Hum Factors 1983;25:409-13.

6. Delvolve N, Queinnec Y. Operators activities at CRT terminals: a behavioural approach. Ergonomics 1983; $26: 329-40$.

7. Aronsson G, Bergqvist U, Almers S. Arbetsorganisation och muskuloskeletala besvär vid bildskärmsarbete [Work organization and musculoskeletal discomforts in VDT work]. Stockholm: Arbetarsmiljöinstitutet, 1992:1—40. (Arbete och hälsa; 1992:4.)

8. Chen PY, Spector PE. Negative affectivity as the underlying cause of correlations between stressors and strains. J Appl Physiol 1991;76:398_- 407.

9. Vassend $O$. Dimensions of negative affectivity, selfreported somatic symptoms, and health-related behaviors. Soc Sci Med 1989;28:29-36.

10. Watson D, Pennebaker JW. Health complaints, stress, and distress: exploring the central role of negative affectivity. Psychol Rev 1989;96:234-54.

11. Bergqvist $U$, Wahlberg J. Skin symptoms and disease during work with visual display terminals. Contact Dermatitis. In press.

12. Kleinbaum DG, Kupper LL, Morgenstern H. Epidemiologic research: principles and quantitative methods. New York, NY: Van Nostrand Reinhold, 1982.

13. Rothman KJ. Modern epidemiology. Boston, MA: Little, Brown and Company, 1986.

14. SAS Institute Inc. SAS users guide: statistics. 5th ed. Cary, NC: SAS Institute Inc, 1985.

15. Belisario A, Modiano A, Fantini A, Gennari E, Nini D, Bacchi L. Sintomatologia oculare e VDT: studio condotto su un gruppo di operatori al video-terminale [Ocular symptoms and video display terminals: research work on a VDT operators group]. G Ital Med
Lav 1988; 10:39-42.

16. Collins MJ, Brown B, Bowman KJ, Caird D. Task variables and visual discomfort associated with the use of VDT's. Optom Vision Sci 1991;68:27-33.

17. Dainoff MJ, Happ A, Crane P. Visual fatigue and occupational stress in VDT operators. Hum Factors 1981; 23:421-38.

18. Rossignol MA, Pechter Morse E, Summers VM, Pagnotto LD. Video display terminal use and reported health symptoms among Massachusetts clerical workers. J Occup Med 1987;29:112-8.

19. Rubino GF, Di Bari A, Turbati M. Epidemiological analysis of discomfort signs. Boll Ocul 1989;68:11323.

20. Yamamoto S. Visual, musculoskeletal and neuropsychological health complaints of workers using videodisplay terminal and an occupational health guideline. Jpn J Ophthalmol 1987;31:171-83.

21. Smith AB, Tanaka S, Halperin W, Richards RD. Correlates of ocular and somatic symptoms among video display terminal users. Hum Factors 1984;26:143-56.

22. Starr SJ, Thompson CR, Shute SJ. Effects of video display terminals on telephone operators. Hum Factors 1982;24:699-711.

23. Howarth PA, Istance HO. The association between visual discomfort and the use of visual display units. Behav Inf Technol 1985;4:131-49.

24. Turner PJ. Visual requirements for VDU operators. Aust J Optom 1982;65:58-64.

25. Pickett CWL, Lees REM. A cross-sectional study of health complaints among 79 data entry operators using video display terminals. J Soc Occup Med 1991; 41:113-6.

26. Yaginuma $Y$, Yamada $H$, Nagai $H$. Study of the relationship between lacrimation and blink in VDT work. Ergonomics 1990;33:799-809.

27. Patel S, Henderson R, Bradley L, Galloway B, Hunter L. Effect of visual display unit use on blink rate and tear stability. Optom Vision Sci 1991;68:888-92.

28. Tsubota $K$, Nakamori K. Dry eyes and video display terminals. N Engl J Med 1993;328:584.

29. Dain SJ, McCarthy AK, Chan-Ling T. Symptoms in VDU operators. Am J Optom Physiol Opt 1988;65: $162-7$.

30. Daum KM, Good G, Tijerina L. Symptoms in video display terminal operators and the presence of small refractive errors. J Am Optom Assoc 1988;59:6917.

31. Wiggins NP, Daum KM. Visual discomfort and astigmatic refractive errors in VDT use. J Am Optom Assoc 1991;62:680-4.

32. Böös SR, Calissendorff BM, Knave BG, Nyman KG, Voss M. Work with video display terminals among office workers: III. ophthalmologic factors. Scand J Work Environ Health 1985;11:475-81.

33. Jaschinski-Kruza W. Eyestrain in VDU users: viewing distance and the resting position of ocular muscles. Hum Factors 1991;33:69-83.

34. Tyrrell RA, Leibowitz HW. The relation of vergence effort to reports of visual fatigue following prolonged near work. Hum Factors 1990;32:341-57.

Received for publication: 30 August 1993 